\title{
A probabilistic approach to detect structural problems in flexible pavement sections at network level assessment
}

\author{
Luis Fuentes, Katherine Taborda , Xiaodi Hu, Emile Horak , Tao Bai \& \\ Lubinda F. Walubita
}

To cite this article: Luis Fuentes, Katherine Taborda, Xiaodi Hu, Emile Horak, Tao Bai \& Lubinda F. Walubita (2020): A probabilistic approach to detect structural problems in flexible pavement sections at network level assessment, International Journal of Pavement Engineering, DOI: $10.1080 / 10298436.2020 .1828586$

To link to this article: https://doi.org/10.1080/10298436.2020.1828586

\section{曲 Published online: 09 Oct 2020.}

Submit your article to this journal $\widetilde{ }$

\section{山 Article views: 148}

Q View related articles 5

View Crossmark data $₫$ 


\title{
A probabilistic approach to detect structural problems in flexible pavement sections at network level assessment
}

\author{
Luis Fuentes (ib $^{\mathrm{a}}$, Katherine Taborda ${ }^{\mathrm{a} *}$, Xiaodi Hu${ }^{\mathrm{b}}$, Emile Horak ${ }^{\mathrm{c}}$, Tao Bai ${ }^{\mathrm{b}}$ and Lubinda F. Walubita ${ }^{\mathrm{a}, \mathrm{d}}$

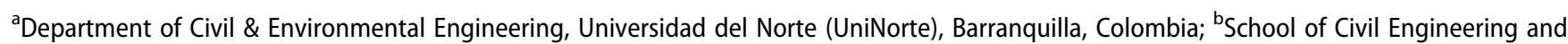

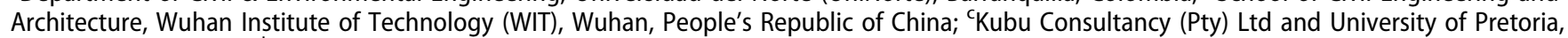 \\ Pretoria, South Africa; ${ }^{\mathrm{d}}$ Texas A\&M Transportation Institute (TTI), The Texas A\&M University System, College Station, TX, USA
}

\begin{abstract}
Presently, most of the road agencies use Non-Destructive (NDT) tools to help them prioritise pavement maintenance and rehabilitation $(M \& R)$ activities at the network level, thus optimising the limited budgetary resources. One of the most widely used NDT techniques for pavement structural evaluations, at the network level assessment, is the Falling Weight Deflectometer (FWD). Using a database comprising of a wide array of typical layer moduli and thicknesses of traditional flexible pavements, that were generated based on multiple Monte Carlo numerical simulations, as a reference datum, this study successfully developed probabilistic models that allow for analysing the condition of a flexible pavement, at the network level, from FWD surface deflection data, namely the Deflection Bowl Parameters (DBPs), to identify which layers of the pavement structure present a probability of structural failure or damage.
\end{abstract}

ARTICLE HISTORY

Received 6 November 2019

Accepted 21 September

2020

\section{KEYWORDS}

Falling weight deflectometer; deflection bowl parameters; logistic model regression; pavement rehabilitation; non destructive testing

\section{Introduction}

The road network constitute one of the largest assets for any country - which is essential for promoting economic, social, and cultural development for its citizens. In this respect, the optimisation of resources targeted towards the conservation and maintenance of the road network have become one of the biggest challenges and a priority issue for many modernday road agencies and highway engineers (Terzi et al. 2012). Thus, it is indispensable for these agencies to have tools that allow them to routinely and timely evaluate the condition of their road networks so that economically efficient interventions are timely executed.

Worldwide, most countries have road networks predominantly consisting of flexible pavements. These are generally multi-layered pavement structures with hot-mix asphalt (HMA) surfacing, typically resting on a base/subbase (untreated or treated) layer that is supported by a subgrade foundation. During service, the whole pavement structure is subjected to repeated traffic loading, fluctuating weather conditions, and other factors that interactively deteriorate the pavement over time. This is particularly critical for the HMA surfacing layer that is directly exposed to repeated traffic loading and changing environmental conditions (Terzi et al. 2012).

Road agencies ordinarily evaluate the performance of their road network, both for functional and structural condition on a routine basis (Rabbi and Mishra 2019). Functional condition refers to the characteristics generally associated with roughness and surface texture (including friction) - which are usually evaluated through parameters such as the International Roughness Index (IRI) (Abudinen et al. 2017, Fuentes et al.
2019), Mean Profile Depth (MPD) (Fuentes et al. 2012, Fuentes and Gunaratne 2010) or Mean Texture Depth (MTD) (Adams and Kim 2014), skid resistance typically expressed as Skid Number (SN) (Fuentes et al. 2010, Fuentes and Gunaratne 2011), etc. On the other hand, road agencies encourage the use of non-destructive testing (NDT) to assess the structural condition of pavement structures to avoid intrusive/destructive testing that could cause additional damage to the pavement. The most commonly used NDT equipment for pavement structural evaluation is the falling weight deflectometer (FWD) that has the potential to quantify the pavement structural strength through back-calculation analysis of the individual layer elastic modulus $\left(E_{i}\right)$ (Walubita et al. 2012, Solanki et al. 2014).

The FWD back-calculation method is one of the most common and quickest way to evaluate and analyse the structural condition of both flexible and rigid pavements (Solanki et al. 2014). However, like any other method, the FWD back-calculation process, too, has its own challenges and inherent limitations. First of all, the software and mathematical expressions to perform the back-calculation analysis use different algorithms - thus, making the results different if different software are used (Alkasawneh 2007). To obtain reliable results, it is mandatory to know beforehand, the thicknesses $\left(h_{i}\right)$ and Poisson ratios $\left(\mu_{i}\right)$ of the layers that make up the existing pavement structure (Alkasawneh 2007, Terzi et al. 2012). For most road agencies without established databases and/or data management systems, these parameters $\left(h_{i}\right.$ and $\left.\mu_{i}\right)$ are simply assumed - thus, making the final results (moduli values) to be relatively variable. In addition, convergence to a local optima due to the use of 'seed' moduli values during the back-calculation 
process, may at times lead to subjective and erroneous final modulus results (Alkasawneh 2007). Furthermore, the number of pavement layers allowed by a given software may be limited, which may become a problem particularly for pavements with multiple overlays, thick pavement structures, or perpetual pavements (Walubita et al. 2010, Horak et al. 2015a, 2015b). This ultimately forces for the compounding and/or use of composite layers, which inherently reduces the accuracy of the back-calculation analysis in terms of the resulting moduli values.

In addition to the above challenges, the FWD back-calculation analysis requires the following general inputs associated with the existing pavement structure: temperature, layer thicknesses, seed modulus, Poisson ratio, loading setup, humidity, moisture condition, etc. (Alkasawneh 2007). This ultimately adds complexity and some degree of unreliability to the FWD back-calculation analysis. Therefore, the question that arises is how some of these challenges can be addressed and/ or minimised to improve accuracy/reliability, gain more confidence, and optimise the FWD back-calculation process. To answer this question, this study proposes a statistical methodology for the analysis of the condition, at the network level, of each individual pavement layer, based on the deflections obtained from the FWD, to allow for an intervention and timely warning of a possible structural deficiency in one or several layers of the pavement structure.

\section{Study objectives and scope of work}

The primary objective of this study is to develop probabilistic models that allow for analysing, at the network level, the condition of a flexible pavement, from FWD surface deflection data, identifying which layer of the pavement structure presents a probability of structural failure or damage. In this regard, the study seeks to provide road agencies with a statistical tool that can help them prioritise maintenance and rehabilitation $(M \mho R)$ activities at the network level while optimising the limited budgetary resources. To achieve this objective, an exhaustive review of the FWD deflection basin parameters (DBPs) proposed in the literature was carried out and, based on the literature findings, the parameters that best described the condition of the pavement layers were studied further in this paper. A database was subsequently generated that encompassed different data sets including the pavement layer thicknesses, and moduli values, along with their corresponding FWD deflection bowl data.

\section{Literature review}

A flexible pavement typically comprises of a HMA surfacing, resting on a base and/or subbase layers (treated or untreated) that are supported by a subgrade foundation. When subjected to traffic loading, the response mechanism involves the induction of three-dimensional stresses, strains, deformations, and displacements within the pavement layers ( $\mathrm{Hu}$ et al. 2010). Of primary importance are the vertical displacements at the surface in the vicinity of the load application points/zone, known as 'deflections', which is the subject of this paper.

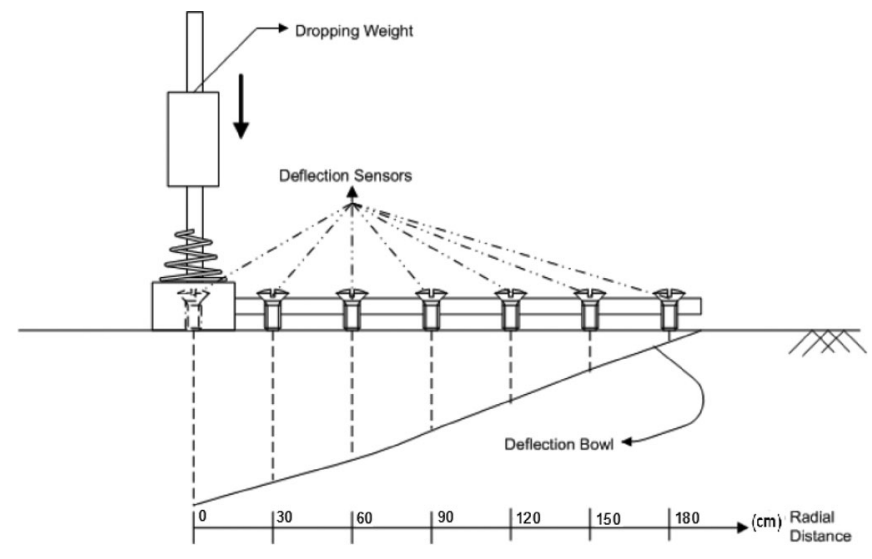

Figure 1. Deflection bowl (Tutumluer 2015).

The Technical Committee on Flexible Roads of the XVII World Road Congress (1983) recognised that the displacement or deflection of the pavement surface of a road subjected to a load, represents the sum of all the vertical deformations in the entire pavement structure and the subgrade (Horak 1987b). Worldwide, vertical deflections is one of the most used criteria to assess the structural condition of a pavement, among others, for the following reasons: the relative simplicity of the measurements, cost-effectiveness, the large amount of historical data that already exists, the historical strong correlation found between deflection data and pavement performance, etc., (Solanki et al. 2014).

Figure 1 shows the general effect of a load on a pavement structure. It should be noted that when a flexible pavement is deflected under wheel loading, the influence of the load will extend over a radial distance approximately $1.0-2.0 \mathrm{~m}$ from the loading point, in three dimensions. The area of pavement deflection under and near the load application is collectively known as the 'deflection bowl or basin' (Horak 2008).

The FWD is a deflection measurement equipment that is used to simulate the load of moving wheels and measure the elastic response at critical points throughout the surface of the deflection region (i.e. deflection basin). This NDT equipment allows for simulating the load of a truck on a pavement by dropping a circular mass from a height that is adjusted according to the required load level (Walubita et al. 2012, 2017). Under the $300 \mathrm{~mm}$ diameter circular plate, a rubber pad is placed to avoid an impact loading effect (Terzi et al. 2012). A standard FWD equipment typically places one deflection sensor directly under the loading plate, and at least six additional deflection sensors are placed along a raise-lower bar, typically every $300 \mathrm{~mm}$ apart. The geophone sensor bar runs from the loading plate towards the tow vehicle. The deflection sensors are velocity transducers (geophones), and the deflections are calculated using a single integration of the velocity response (see Figure 2).

Researchers have developed several Deflections Bowl Parameters (DBPs) that can be derived from the measured deflection bowl to verify the structural integrity of in-service pavements; to relate to the critical pavement response, and, to estimate the in-situ layer moduli of the pavement using back-calculation techniques. However, many deflection indicators were developed prior to the development of the FWD 


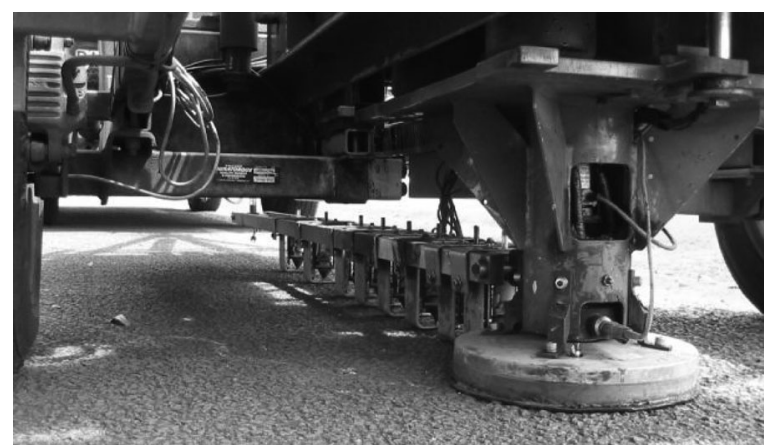

Figure 2. Falling weight deflectometer (FWD) configuration (Zheng et al. 2019).

from data that were obtained from devices such as the Benkelman beam, or vibratory devices such as the Road Rater (RR) or Dynaflect - however, these devices were only able to measure deflection at one point (Hossain and Zaniewski 1991). Table 1 summarises the most common DBPs proposed in the literature and their mathematical expressions. As discussed subsequently, some of these DBPs have been reported to provide satisfactory correlative results with the pavement structural condition and performance - while others have inherent challenges and limitations.

The $D_{0}$ parameter presented in Table 1 corresponds to the deflection measured directly under the point of load application. It describes how the pavement behaves as a whole structure, but gives no indication of the individual mechanical properties of each layer and how the layers are going to perform against fatigue or permanent deformation (Shahin 2005). Studies conducted by Whitcomb (1982) and Stubstad and Connor (1983) proved that $D_{0}$ should not be taken as a sufficient and valid parameter, on its own, to determine the structural condition of a pavement, much less to perform back-calculation analysis to determine the moduli of the existing layers. Moreover, Horak (1987b) and Joubert (1992) showed that similar maximum deflections $\left(D_{0}\right)$ can be obtained on pavement sections with completely different material characteristics and/or different deflection basin shapes. It is important to highlight that $D_{0}$ was originally proposed to be measured using the Benkelman beam device; however, the parameter can also be measured using a FWD equipment.

Dehlen (1961) proposed a simplified empirical method to evaluate pavement performance using the Benkelman beam. Dehlen (1961) suggested taking the deflections measurements at $75 \mathrm{~mm}$ intervals in order to plot the whole deflection bowl. Based on these measurements, an indicator known as the Radius of Curvature $\left(\mathrm{R}_{\mathrm{o}} \mathrm{C}\right)$ was proposed. The $\mathrm{R}_{\mathrm{o}} \mathrm{C}$ at the point of maximum deflection in the deflection bowl is obtained by determining the circle, which best fits the curve over the central $250 \mathrm{~mm}$ radius. Furthermore, Dehlen (1962) showed that the radius of curvature was an acceptable indicator of flexural stresses. Hence, it could be used to design against flexural cracking. In addition, Dehlen's results suggested that the radius of curvature was sensitive to the HMA surfacing only if it was relatively thick (more than 50 or $75 \mathrm{~mm}$ ). The $\mathrm{R}_{\mathrm{o}} \mathrm{C}$ primarily depended on the moduli of the base and subbase layer materials, but it was fairly insensitive to the subgrade.
However, as technology evolved, impulse load deflection devices (i.e. the FWD) were introduced to overcome some of the challenges of the Benkelman beam such as labour intensiveness, efficiency (speed of measurements), etc. Considering that FWD devices are able to capture the entire deflection response in the vicinity of the load application point, various researchers including Rohde and Van Wijk (1996) and Horak et al. (2015a) used this information to propose alternative deflection bowl parameters in the evaluation of the pavement structural capacity in lieu of the $\mathrm{R}_{\mathrm{o}} \mathrm{C}$ parameter. One such parameter is the Base Layer Index (also known as the Surface Curvature Index), which according to Horak et al. (2015a) exhibited a good correlation with $\mathrm{R}_{\mathrm{o}} \mathrm{C}$. Additionally, Horak (1987a, 1987b) reported that this parameter has a high sensitivity to most changes in the pavement structural parameters, specially the surfacing and base layer to a depth of up to $75 \mathrm{~mm}$ from the top of the surface, but was insensitive to changes of the subgrade elastic modulus.

In 1981, Hoffman and Thompson (1981) developed the 'Area' Parameter (A), which was a mirror/continuation of an earlier work done by Vaswani (1971) who proposed the spreadability $(S)$ factor combining the five sensor readings of a Dynaflect device. This 'Area' parameter (A) combines all the measured deflections in the basin. By combining the different deflection measurements into one indicator, the effect of a possible sensor malfunction is minimised. Furthermore, Hoffman and Thompson (1981) concluded that the deflection basin 'Area', in particular, is a good parameter for characterising the entire pavement structure; while Saleh (2015a) stated that this parameter has a good relationship with the pavement stiffness (i.e. elastic modulus). However, it should be noted that this parameter has not been widely utilised in pavement evaluation because there was no scale rating criteria that was developed to rank the pavement structures between these two extreme conditions (poor pavement structure and a high quality pavement structure) provided in the literature (Saleh 2015a).

The Surface Curvature Index (SCI) was one of the earliest used DBPs - it is calculated as the difference between $D_{0}$ and the deflection located at the second sensor $D_{300}$ $(300 \mathrm{~mm})$, as shown in Table 1 . Based on the analysis of standard pavement structures in the State of Victoria (Australia), Anderson (1977) suggested that this parameter could be used as an indicator of the strength of the surface layer of a pavement. The SCI was one of the most relevant parameter related to the maximum horizontal strain at the bottom of HMA layer (Horak 1987a, 1987b). However, it should not be used to determine the subgrade strains because of its corresponding poor correlations, with a coefficient of determination $\left(R^{2}\right)$ less than $38 \%$, i.e. $R^{2}<38 \%$ (Federal Highway Administration (FHWA) 2016). Xu et al. (2002) studied and also validated the relationship between the DBPs and the layer conditions, observing that the SCI was the most sensitive parameter to the HMA layer properties including the modulus.

On the other hand, using deflection data obtained from a second generation Road Rater device, Kilareski and Anani (1982) carried out a study to determine the properties of the in-situ layers to estimate the remaining useful life of a pavement structure. The study suggested two indicators, namely: 
Table 1. Literature review summary - deflection bowl parameters (DBPs).

\begin{tabular}{|c|c|c|c|c|c|c|}
\hline No & ID parameter name & Significance of parameter & Measuring device & Formula & Thresholds & Reference \\
\hline 1 & $\mathrm{D}_{0}$ Maximum deflection under & Structural strength of all layers & Benkelman beam & First measured deflection & $\mathrm{S}<500 \mathrm{~W} 500-750 \mathrm{Se}$ & Kennedy and Lister \\
\hline 2 & $\begin{array}{l}\text { Load (micron) } \\
\text { RoC Radius of Curvature (m) }\end{array}$ & $\begin{array}{l}\text { Structural condition of surfacing and } \\
\text { base condition }\end{array}$ & Curvaturemeter & $\begin{array}{l}R_{0} C=L^{2} /\left[2 D_{0}\left(1-\frac{D_{300}}{D_{0}}\right)\right] \text { Where } L=127 \mathrm{~mm} \text { in } \\
\text { the Dehlen curvature metre and } 200 \mathrm{~mm} \text { for the FWD }\end{array}$ & $\begin{array}{c}>750 \\
\mathrm{~S}>100 \mathrm{~W} 50-100 \mathrm{Se}< \\
50\end{array}$ & $\begin{array}{c}\text { (1978) } \\
\text { Dehlen (1962) }\end{array}$ \\
\hline 3 & $\begin{array}{l}\text { SCI (BLI) Surface curvature Index } \\
\text { (micron) }\end{array}$ & Upper layer condition & $\begin{array}{l}\text { FWD Benkelman beam } \\
\text { Road rater }\end{array}$ & $D_{0}-D_{300}$ & $\begin{array}{c}\mathrm{S}<200 \mathrm{~W} 200-400 \mathrm{Se} \\
>400\end{array}$ & Anderson (1977) \\
\hline 4 & $\begin{array}{l}\text { BDI(MLI) Middle layer Index } \\
\text { (micron) }\end{array}$ & Base layer condition & FWD Road rater & $D_{300}-D_{600}$ & $\begin{array}{c}\mathrm{S}<115 \mathrm{~W} 115-225 \mathrm{Se} \\
>225\end{array}$ & $\begin{array}{l}\text { Kilareski and Anani } \\
\text { (1982) }\end{array}$ \\
\hline 5 & BCI (LLI) Lower layer Index (micron) & Subgrade condition & FWD Road rater & $\begin{array}{c}D_{600}-D_{900}\left(\text { USA) } D_{900}-D_{1200} \text { (Finland) } D_{1200}-D_{1500}\right. \\
\text { (Estonia) }\end{array}$ & $\begin{array}{c}\mathrm{S}<50 \mathrm{~W} 50-100 \mathrm{Se}> \\
100\end{array}$ & $\begin{array}{l}\text { Kilareski and Anani } \\
\quad(1982)\end{array}$ \\
\hline 6 & AREA Area (in) / (mm) & Upper layer condition & FWD & $\begin{array}{l}A=\frac{6\left(D_{0}+2 D_{12}+2 D_{24}+D_{36}\right)}{D_{0}} \\
A=\frac{150\left(D_{0}+2 D_{300}+2 D_{600}+D_{900}\right)}{D_{0}}\end{array}$ & $\mathrm{~N} / \mathrm{A}$ & $\begin{array}{l}\text { Hoffman and Thompson } \\
\text { (1981) }\end{array}$ \\
\hline 7 & $\begin{array}{l}\text { AUPP Area under pavement } \\
\text { performance (in) }\end{array}$ & Upper layer condition & FWD & $A U P=\frac{5 D_{0}+2 D_{12}+2 D_{24}+D_{36}}{D_{0}}$ & $\begin{array}{c}\mathrm{S}>7.4 \mathrm{~W} 6.6-7.4 \mathrm{Se}< \\
6.6\end{array}$ & $\begin{array}{c}\text { Garg and Thompson } \\
\text { (1997) }\end{array}$ \\
\hline 8 & AL1 Area Indices & Upper layer condition & FWD & $A l_{1}=\frac{D_{0}+D_{300}}{2 D_{0}}$ & $\begin{array}{c}\mathrm{S}>0.84 \mathrm{~W} 0.75-0.84 \mathrm{Se} \\
<0.75\end{array}$ & $\begin{array}{l}\text { Hoffman and Thompson } \\
\text { (1981) }\end{array}$ \\
\hline 9 & AL2 Area Indices & Middle layer condition & FWD & $A l_{2}=\frac{D_{300}+D_{600}}{2 D_{0}}$ & $\begin{array}{c}\mathrm{S}>0.54 \mathrm{~W} 0.36-0.54 \mathrm{Se} \\
<0.36\end{array}$ & $\begin{array}{l}\text { Hoffman and Thompson } \\
\text { (1981) }\end{array}$ \\
\hline 10 & AL3 Area Indices & Middle layer condition & FWD & $A l_{3}=\frac{D_{600}+D_{900}}{2 D_{0}}$ & $\begin{array}{l}\mathrm{S}>0.31 \mathrm{~W} 0.19-0.31 \mathrm{Se} \\
<0.19\end{array}$ & $\begin{array}{l}\text { Hoffman and Thompson } \\
\text { (1981) }\end{array}$ \\
\hline 11 & AL4 Area Indices & Lower layer condition & FWD & $\begin{array}{c}A l_{4}=\frac{2 D_{0}}{\left[D o+D_{000}\right.} \\
50\end{array}$ & $\begin{array}{c}\mathrm{S}>0.18 \mathrm{~W} 0.14-0.18 \mathrm{Se} \\
<0.14\end{array}$ & $\begin{array}{l}\text { Hoffman and Thompson } \\
\text { (1981) }\end{array}$ \\
\hline 12 & Area Ratio & Subgrade Condition & Deflectograph & $A r=\frac{J 0}{900 * D_{0}}\left[\frac{D U+D_{900}}{2}+\sum_{i=50} D_{i}\right.$ & $\begin{array}{c}\mathrm{S}>0.25 \mathrm{~W} 0.1-0.25 \mathrm{Se} \\
<0.1\end{array}$ & Saleh (2015a) \\
\hline
\end{tabular}

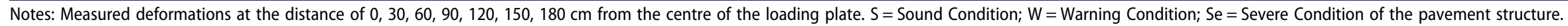




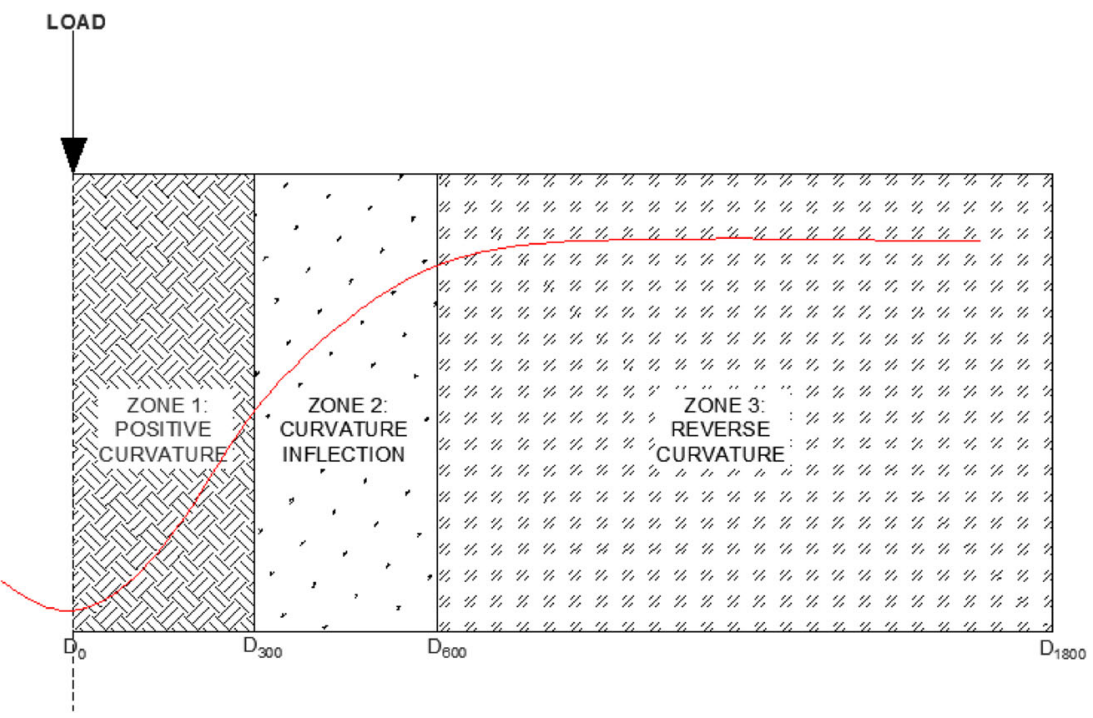

Figure 3. Curvature zones of a deflection basin (Horak 2008).

(a) the Base Damage Index (BDI) - indicator of damage in the base layer, and, (b) the Base Curvature Index (BCI) - indicator of curvature of the subgrade. The BDI parameter is used for characterising the stiffness of the intermediate layers of the pavement structure, which may correspond to the base layers (Horak 1987b, Xu et al. 2002). On the other hand, the parameter BCI, defined as the difference in deflections at 600 and $900 \mathrm{~mm}$ from the centre of the load, reflects strongly on the structural capacity of the lower layers such as the subbase or subgrade (Horak 1987a, 1987b, Kim et al. 2000).

Another parameter associated with the analysis of the deflection bowl is the Area Under Pavement Profile $(A U P P)$. Based on a study on the MnRoad test sections, Garg and Thompson (1997) demonstrated a good relationship between the AUPP and the mechanical response of the HMA layers. These researchers also concluded that the AUPP parameter can be used for estimating the tensile strains at the bottom of the HMA layer with good statistical precision, i.e. $R^{2} \geq 90 \%$ (Kim and Park 2002, FHWA 2016, Saleh 2016). Furthermore, Xu et al. (2002) found a good relationship between the AUPP parameter and the HMA layer properties, which is consistent with the findings by Garg and Thompson (1997).

In a South African study by Horak (1987a, 1987b), various performance indicators and FWD DBPs under a heavy vehicle simulator (HVS) were evaluated. Horak's studies summarised the commonly used DBPs that were found to be significant, concluding that only the first five indicators in Table 1 provided good relationships with the behavioural state and structural capacities of the pavement and in turn, with the condition of the individual layers of the pavement structure. Furthermore, relationships between DBPs and critical strain values were developed as an alternative to back-calculation of the layer modulus and as a verification of the South African mechanistic design procedure (Vrtis 2017).

Moreover, Horak and Emery (2006) and Horak (2008) proposed a simplified approach through the use of three zones to interpret the deflection basin data, as illustrated in Figure 3. The three zones described in Figure 3 are identified by the original parameters proposed by Anderson (1977) and Kilareski and Anani (1982), but were renamed as: Base layer index (BLI), Middle layer index (MLI), and Lower layer index (LLI), respectively, which were validated through an assessment of different pavement configurations in South Africa (Horak 2008). Horak et al. (2015a, 2015b) recommended the use of the deflection bowl parameters as an alternative evaluation of the pavement structures. Zone 1 is normally within a radius of no more than $300 \mathrm{~mm}$ from the loading point. In this zone, the deflection bowl has a positive curvature. Horak (2008) suggests that Zone 1 is correlated typically to the BLI or $\mathrm{R}_{\mathrm{o}} \mathrm{C}$. Zone 2 is the zone where the deflection bowl switches from a positive curvature to a reverse (negative) curvature and is often referred to as the inflection zone. Zone 2 normally lies from about $300 \mathrm{~mm}$ to about $600 \mathrm{~mm}$ from the loading point. This zone is mainly affected by the mechanical properties of the base and more so the subbase layer. Furthermore, Horak (2008) suggests that Zone 2 is correlated to the MLI. Zone 3 normally stretches from distances greater than $600 \mathrm{~mm}$ from the loading point and its extent will depend on the actual depth of the pavement structure and on the structural response of the subgrade. Zone 3 is considered to be correlated to the LLI (Horak 2008, Horak et al. 2015a, 2015b).

Saleh (2015b) used the deflectograph device to evaluate the structural condition of the pavement network, and proposed the Normalized Area Ratio (Ar), arguing that this parameter provides useful information regarding the pavement structural capacity above the subgrade. For a strong pavement structure over a strong subgrade, the value of $A r$ will be large. However, for a weak pavement structure over a weak subgrade, the value of $A r$ will be very small. Saleh (2016) demonstrated that the $A r$ is sensitive to the subgrade condition and was very well correlated to the compressive strains on the top of the subgrade with a $R^{2}=90.5 \%$. Such information about this parameter (i.e. $A r$ ) is critical in assisting road asset managers to determine the 
$M \diamond R$ needs as well as the budgetary requirements (Saleh 2015b).

Moreover, different studies have used alternative techniques such as an Adaptive-Network-based Fuzzy Inference System (ANFIS) combined with Finite Element Modeling (FEM) for the inverse analysis of the multi-layered flexible pavement structures subjected to dynamic loading (Gopalakrishna and Kumar 2010). In addition, Terzi et al. (2012) introduced a methodology based on Data Mining to the thicknesses of the layers of a flexible pavement structure through subsequent calculation techniques based on pavement deviations, without core extraction data. The Data Mining techniques included linear regression, multilayer perceptron (the back-propagation neural network), pace regression, SMOreg, KStar, M5P, and decision table. However, the key challenge associated with these methods is their complexity and resource intensiveness - and hence, not routinely nor widely used.

Recent studies have also indicated that the DBPs are an adequate alternative to make pavement evaluation decisions at the network level assessment (Horak et al. 2015b, Rabbi and Mishra 2019). Using a Finite Element Analysis approach, Rabbi and Mishra (2019) validated the threshold values proposed for different DBPs (i.e. BDI (or MLI), BCI (or LLI)) that could be used to detect problems in specific pavement layers (Table 1). Results from the numerical modelling effort indicated that, at the network level, typically used DBP threshold values for the base and subgrade layers were in general agreement with typical ranges of layer moduli observed in practice. However, the DBP corresponding to the surface layer (SCI or BLI) was significantly affected by moduli of the underlying layers, and therefore, cannot be used as the primary indicator of surface layer conditions. It should be noted that Rabbi and Mishra (2019) validated these threshold indicators using a graphical approach based on engineering judgment. In addition, Rabbi and Mishra (2019) confirmed the approach advocated by Horak et al. (2015a, 2015b) that the DBPs could be used to accurately detect the layers with damage/failure within a pavement structure. Furthermore, the authors claimed that one of the primary advantage of a pavement assessment based on the analysis of DBPs is that it does not rely on pavement layer thickness data. However, Rabbi and Mishra (2019) used fixed layer thicknesses in all the analysed pavement sections, which might suggest that their findings may not be exhaustive for pavement sections with different dimensions. Finally, Rabbi and Mishra (2019) do recognise and acknowledge that temperature has a significant effect on the viscoelastic behaviour, specifically of HMA, but for the sake of simplicity, this variable was not taken into account in their study.

In general, DBPs are defined as indicators that use the deflection curve produced by the FWD as a means to evaluate and identify problems within a pavement structure and, thereafter, decide on the $M \mho R R$ strategies. When compared with the back-calculation method, the use of these parameters will generally not produce detailed results, but only an indication of the structural condition of the pavement structure. If the elastic modulus $(E)$ of the layers need to be determined, back-calculation methods need to be used. However, for field use, the
DBPs general provide sufficient structural evaluation of the pavement condition (Horak et al. 2015b).

\section{Study methodology}

The study methodology involved a two-phase work plan, namely deflection analysis and probabilistic modelling. The deflection analysis, covering the HMA surfacing, base, and subgrade layers, included generation of the deflection basins versus sensor distance and computation of the DBPs as a function of the respective pavement layer modulus. Probabilistic modelling included statistical analysis and use of Logistic/ Logit regression models to predict the probability of failure/ damage as a function of the DBPs for different pavement layers.

In order to identify which DBPs could be used to evaluate the likelihood that a specific pavement layer would exhibit structural failure or damage, the mechanical response (deflections) of different pavement structures was modelled in this study. A typical 3-layer pavement structure comprising of a HMA surfacing with thicknesses ranging from 100 to $140 \mathrm{~mm}$, overlying a thick granular layer (combining the effect of both base and subbase layers), with thicknesses ranging from 250 to $550 \mathrm{~mm}$, constructed over a subgrade layer of infinite depth was modelled in this study. Note that combining the base and subbase layers as executed in this study, is a simplification approach generally implemented in most DBPs studies for network level applications, where the base and subbase material properties are assumed not to vary significantly (Horak 1987b, Xu et al. 2002, Horak and Emery 2006, Horak 2008, Horak et al. 2015b, Rabbi and Mishra 2019).

Typical material properties, conforming to the Colombian standards, for the HMA, the granular, and subgrade, were used. Note that both the pavement structure and material properties were selected using the Colombian standards as the reference datum (Instituto Nacional de Vías, Colombia (INVIAS) 2018). Table 2 details the ranges of the layer thicknesses and material properties used in the modelling process as well as formulation of the probabilistic functions. This approach is similar to the approach used by Horak and Emery (2006), (Horak et al. 2015b) based on typical flexible pavement structures used in South Africa and mechanistically analysed as originally described by Maree and Bellekens (1991) and correlated with actual FWD deflection measurements.

In addition to conforming to the Colombian standards, the material properties in Table 2 are also consistent with the literature publications (Rabbi and Mishra 2019). It is important to note that in this study, the upper limit of the moduli presented in Table 2 was taken to be representative of a 'well-performing' pavement layer, whereas the lower limit indicated a 'poor' pavement layer. Layer thicknesses were varied considering that, at the network level, road agencies do not necessarily have information regarding the actual condition of the existing pavement structures.

The Monte Carlo simulation technique (Harrison 2010) was used to generate 5000 scenarios by randomly varying the elastic modulus and thickness of each layer within the limits presented in Table 2. Uniform distributions were utilised in the Monte Carlo simulations using the parameters listed in 
Table 2. Pavement structure and layer material details.

\begin{tabular}{|c|c|c|c|c|c|c|c|}
\hline \multirow[b]{2}{*}{ No } & \multirow[b]{2}{*}{ Layer } & \multicolumn{2}{|c|}{ Thickness (mm) } & \multicolumn{3}{|c|}{ Elastic Modulus (MPa) } & \multirow[b]{2}{*}{ Poisson ratio $(\mu$} \\
\hline & & Minimum & Maximum & Minimum & Typical & Maximum & \\
\hline 1 & HMA surface & 100 & 140 & 400 & 2500 & 4000 & 0.30 \\
\hline 2 & Middle layer & 250 & 550 & 20 & 210 & 280 & 0.35 \\
\hline
\end{tabular}

Table 2 to generate the pavement layer thicknesses and moduli values for 5000 scenarios, which were considered adequate for this particular study. Note that while increasing the simulations to over 5000 , i.e. 7500 or 10,000 , did not significantly affect the results, increasing the population size does consume a significant amount of computational time.

Poisson's ratio values were kept constant using the values shown in Table 2. Considering that this study aimed at providing an analytical (statistical) tool for the decision making process at the network level, all the pavement layers were modelled as linear-elastic without consideration of the complex viscoelastic nature of HMA and stress-dependent behaviour of unbound (base and subgrade) materials. However, one has to recall that different researchers have shown that these assumptions do not necessarily limit the applicability of the findings obtained through this simplified modelling approach, but can be mirrored even for more complex analyses (Tarefder and Mesbah 2014, Rabbi and Mishra 2019).

For each scenario, the mechanical response (deflections) and corresponding DBPs were obtained using the PITRA PAVE software, developed by the Materials and Pavements Unit of the Transportation Infrastructure Program (PITRA) of the Lanamme UCR-Costa Rica. The responses were calculated using the following load level as a reference datum: 40 $\mathrm{kN}$ (FWD) and a contact pressure of $689 \mathrm{kPa}$ (load plate diameter $300 \mathrm{~mm}$ ). Deflections were estimated based on the typical configuration of the FWD sensors, namely $0,300,600$, 900, 1200,1500 , and $1800 \mathrm{~mm}$. As previously stated, in this study, all the HMA moduli values were corrected and normalised to a reference temperature of $20^{\circ} \mathrm{C}$, which is in line with the AASHTO (1993) pavement design guide and also close to the ambient temperature.

\section{Deflection analysis and probabilistic models}

The main aim of this study was to formulate statistical models to estimate the failure probability of each pavement layer based on deflection measurements. Taking into account that the DBPs are widely used as a tool to evaluate the structural condition of a pavement, the first task involved generating different Logistic models for each individual layer, to define the indicator that best estimates the probability that it exhibits a structural failure condition. An analysis was conducted for each pavement layer, using the generated deflection database and corresponding DBPs. Considering $Z=0$ for 'good condition', and $Z=1$ for 'failure condition', a binary Logit model, expressed in Equation (1), was formulated to estimate the probability of failure of each layer with respect to relevant DBPs.

$$
P(Z=1 \mid X)=\frac{1}{1+e^{-\left(\beta_{0}+\beta_{1} * X\right)}}
$$

Where $Z$ is the dependent variable, $P(Z=1)$ is the predicted probability that the specific pavement layer has failed; $\beta_{0}$ and $\beta_{1}$ are the regression coefficients, and $X$ is the independent variable (i.e. selected DBP to predict the condition of a particular layer). The maximum likelihood procedure was used to estimate the model parameters $\beta_{0}$ and $\beta_{1}$ for each of the specified models of each pavement layer using the statistical software RStudio (2019). The threshold values to define whether the pavement layers were considered to be in a failure condition were as follows: HMA layers with modulus values lower that $600 \mathrm{MPa}$, intermediate layers with modulus values lower than $60 \mathrm{MPa}$, and a subgrade with modulus values lower than $20 \mathrm{MPa}$. For these particular scenarios, the dependent variable was assigned a value of one (i.e. $Z=1$ ). The estimates of the maximum likelihood parameters calculated for the models proposed for each pavement layer are discussed in the subsequent text.

\section{Surface layer analysis - the HMA layer}

To better understand the role that the surface layer plays in the deflection response of the pavement structure, a sensitivity analysis was carried out. Figure 4 illustrates how the elastic modulus of the surface layer affect the deflection basin when other properties (i.e. moduli and thicknesses) of the other layers of the pavement structure are kept constant. It is observed that when the elastic modulus of the surface layer varies, only the deflections measured close to the load are affected. In this case, only up to a distance of $600 \mathrm{~mm}$ from the loading plate. Results from Figure 4 imply that deflections measured at distances of more than $600 \mathrm{~mm}$ from the loading point are hardly affected by the properties of the surface layer. This suggests that the DBPs that should be considered to study the surface layer should only consider deflections measured up to a distance of $600 \mathrm{~mm}$ from the application of the load.

Table 3 presents details of the different models proposed to analyse the surface layer based on different DBPs using

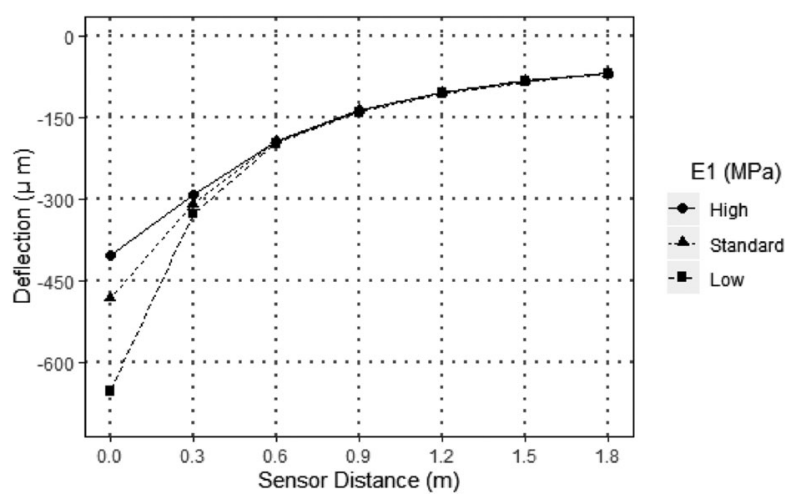

Figure 4. Effect of HMA modulus variation on deflection basins. 
Table 3. Statistical results from probabilistic modelling - surface layer.

\begin{tabular}{|c|c|c|c|c|c|c|c|}
\hline \multicolumn{8}{|c|}{ Surface layer (HMA) } \\
\hline \multirow[b]{2}{*}{ DBP's } & \multicolumn{2}{|c|}{ Parameters } & \multirow[b]{2}{*}{ OR } & \multirow[b]{2}{*}{$\mathrm{AIC}$} & \multirow[b]{2}{*}{ Log likelihood } & \multirow[b]{2}{*}{$\mathrm{BIC}$} & \multirow[b]{2}{*}{ C-statistic } \\
\hline & $\beta_{0}$ & $\beta_{1}$ & & & & & \\
\hline $\mathrm{D}_{0}$ & $\begin{array}{c}-0.644 \\
(4.46 \mathrm{e}-11)^{*}\end{array}$ & $\begin{array}{c}-0.0010 \\
(4.62 \mathrm{e}-15)^{*}\end{array}$ & 0.99 & 4944.7 & -2470 & 4957.6 & 0.51 \\
\hline RoC & $\begin{array}{c}11.370 \\
(2 \mathrm{e}-16)\end{array}$ & $\begin{array}{c}-0.0000831 \\
(2 \mathrm{e}-16)\end{array}$ & 1.00 & 1809.2 & -902.0 & 1822.2 & 0.95 \\
\hline AUPP & $\begin{array}{c}943.96 \\
(2 e-16)\end{array}$ & $\begin{array}{l}-137.6 \\
(2 \mathrm{e}-16)\end{array}$ & 0.00 & 192.49 & -94.24 & 205.5 & 0.98 \\
\hline BLI & $\begin{array}{c}-12.410 \\
(2 \mathrm{e}-16)\end{array}$ & $\begin{array}{c}0.037 \\
(2 e-16)\end{array}$ & 1.038 & 1914 & -954.97 & 1926.9 & 0.96 \\
\hline $\mathrm{AL} 1$ & $\begin{array}{c}1383 \\
(0.985)\end{array}$ & $\begin{array}{l}-1798 \\
(0.985)\end{array}$ & 0.00 & 4.00 & $-4.808 \mathrm{e}-07$ & 17.03 & 0.99 \\
\hline \multicolumn{3}{|c|}{ Criterion (preferred value) } & & Lower & Higher & Lower & Higher \\
\hline
\end{tabular}

*The values in parentheses correspond to the $p$-value of the corresponding parameter.

Equation (1). Note that only DBPs that have been associated with the surface layer in the literature were considered (see Table 1). Furthermore, Table 3 includes different statistical indicators (AIC, BIC, Log Likelihood, C-statistic, and OR) that allow for evaluating the quality of the proposed models. Therefore one could identify which DBP is the best that describes the integrity of the surface layer. The Akaike information criterion (AIC) is an estimator of the relative quality of statistical models for a given set of data (Wang and Liu 2006). Given a collection of models for a given set of data, the AIC estimates the quality of each model, relative to the other models. Lower value of AIC suggests 'better' model, which is only a relative measure of the model fit.

The Bayesian information criterion (BIC) is a criterion for model selection among a finite set of models (Wang and Liu 2006). It is based on the likelihood function and it is closely related to the AIC. The model with the lowest BIC is generally preferred. The Log Likelihood value is a measure of the goodness of fit for any model. When comparing models, higher values of the Log Likelihood are associated with models with better predictive capabilities.

The C-statistic (sometimes called the 'concordance' statistic or C-index) is a measure of the goodness of fit for binary outcomes in a logistic regression model (Pencina and D'Agostino 2015). It is equal to the area under the Receiver Operating Characteristic (ROC) curve and ranges from 0.5 to 1.0. Higher values of the C-statistics are preferred for model strength and high predictive accuracy. Values over 0.8 indicate a strong model. A C-statistic of 0.5 indicates that the model is only as good at predicting the outcome as a random chance (i.e. no discrimination), which would mean a very poor model indeed with low correlative and predictive accuracy.

Finally, in Logistic regression models, the OR-odd ratioused to measure the association, in terms of the probabilities, between the dependent variable (i.e. the condition of the pavement layer) and the independent variable (i.e. DBP) (Hosmer et al. 2013). OR greater than 1 (i.e. $O R>1$ ) indicates increased occurrence of the event - in other words, it states that an increase in the DBP is associated with a higher odds of the surface layer to present structural failure/damage. Considering the nature of the DBPs, an OR $\leq 1$ would indicate that this parameter is not a good estimator of the structural integrity of the surface layer.
If one analyses the statistics presented in Table 3, the following conclusions can be drawn. The model using AL1 can be discarded considering that its parameters $\left(\beta_{0}\right.$ and $\left.\beta_{1}\right)$ are not statistically significant (i.e. $p$-values higher than 0.05 ), hence, it presents an unstable model with an $\mathrm{OR}$ value approaching zero. The model using $\mathrm{R}_{\mathrm{o}} \mathrm{C}$ presents an $\mathrm{OR}$ value of one, suggesting that the probability of failure of the pavement surface layer is independent of the $R_{o} C$ variable, hence, it can also be discarded. The model using $D_{o}$ presents an OR value less that one, which makes no sense from a physical stand point, hence, it can also be discarded. The model using AUPP presents an unstable solution with an OR value approaching zero. The model based on the BLI presents adequate statistics and a robust C-statistic with a quantitative value of 0.96 . Therefore, the DBP that best fits to predict the condition of the surface layer (HMA) is the BLI, which is consistent with the literature (see Table 1). The mathematical expression to calculate the BLI can be found in Table 1. Table 4 details the model parameters defined in Equation (1) for the HMA surfacing layer using the BLI as a predictive variable. In general, the results show a good fit for the model with $p$-values significantly less than 0.05 at $95 \%$ confidence level (CL).

The coefficient $\beta_{1}$ in Table 4 can be used to estimate the OR. In this case, the OR $(1.04)=\exp \left(0.037{ }^{*} 1 \mu \mathrm{m}\right)=1.038$, which implies that for one-unit increase in the BLI, one would expect to see a $4.0 \%$ increase in the odds of having a structural problem or failure/damage in the HMA surfacing layer.

Equation (1), with appropriate parameters taken from Table 4, was used to estimate the probability of failure of the HMA surfacing layer with respect to the BLI. The corresponding results are plotted in Figure 5.

As exemplified in Figure 5, a pavement structure with a BLI value close to $365 \mu \mathrm{m}$ would imply that the probability that its HMA surfacing layer presents structural failure is $75 \%$. Results presented in Figure 5 are consistent with the threshold values proposed by Horak et al. (2015a), where pavement structures

\begin{tabular}{|c|c|c|c|c|c|}
\hline Parameter & Estimate & S.E & Z & $p$-value & OR \\
\hline$\beta_{0}$ & -12.4 & 0.42 & -28.98 & $<0.001$ & \\
\hline$\beta_{1}$ & 0.037 & 0.0012 & 29.25 & $<0.001$ & 1.038 \\
\hline Criterion & & & & $<0.05 @ 95 \% \mathrm{CL}$ & $>1.00$ \\
\hline
\end{tabular}

Note: Legend: S.E. $=$ Standard Error; $Z=$ Standard Score; OR = Odds Ratio. 


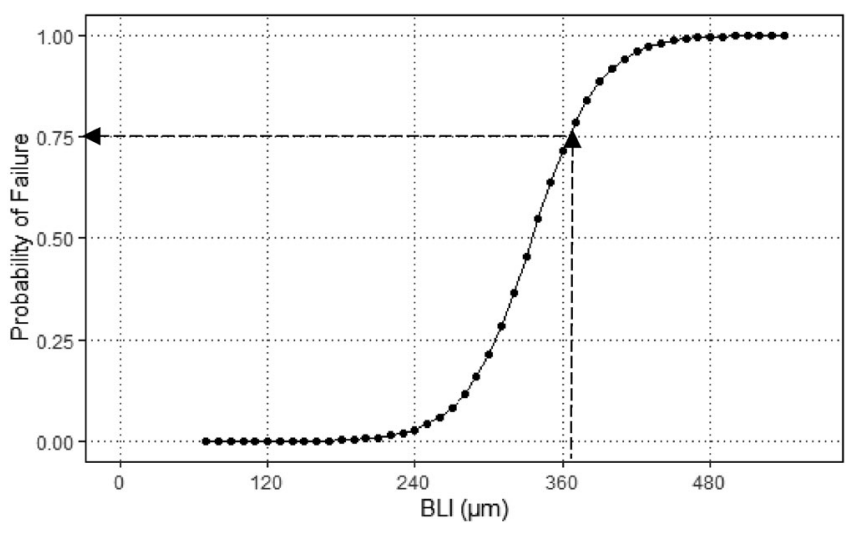

Figure 5. BLI probability of failure - HMA surfacing layer.

with $\mathrm{BLI}<200 \mu \mathrm{m}$ are considered to be in sound condition. Pavement structures with $200 \mu \mathrm{m}<\mathrm{BLI}<400 \mu \mathrm{m}$, on the other hand, are highlighted with a warning condition, and pavement structures with BLI $>400 \mu \mathrm{m}$ are considered to be in a critical condition needing immediate attention (Table 1).

Finally, Figure 6 shows a sensitivity analysis of the BLI as the HMA modulus was varied. From the figure, one can distinguish that the slope of the relationship BLI versus E1 only stabilises for modulus higher than $2000 \mathrm{MPa}$ (i.e. layers in good condition). This further confirms that the BLI is highly sensitive to detect problems in the HMA surfacing layer.

\section{Middle layer analysis - the granular base layer}

For the second layer, a sensitivity analysis was carried out to evaluate the effects of the variation of the elastic modulus of the base layer on the deflection response of the pavement structure. Figure 7 shows that variations in the middle layer modulus (E2) hardly affects the deflections measured at distances of more than $900 \mathrm{~mm}$ from the loading point.

Table 5 presents details and the corresponding results of the different probabilistic models proposed to analyse the middle base layer based on the relevant DBPs using Equation (1).

From the statistics presented in Table 5 , it can be concluded that all the DBPs have parameters $\left(\beta_{0}\right.$ and $\left.\beta_{1}\right)$ that are statistically significant (i.e. $p$-values lower than 0.05 ). It can be highlighted that parameters AUPP and AL2 present OR values

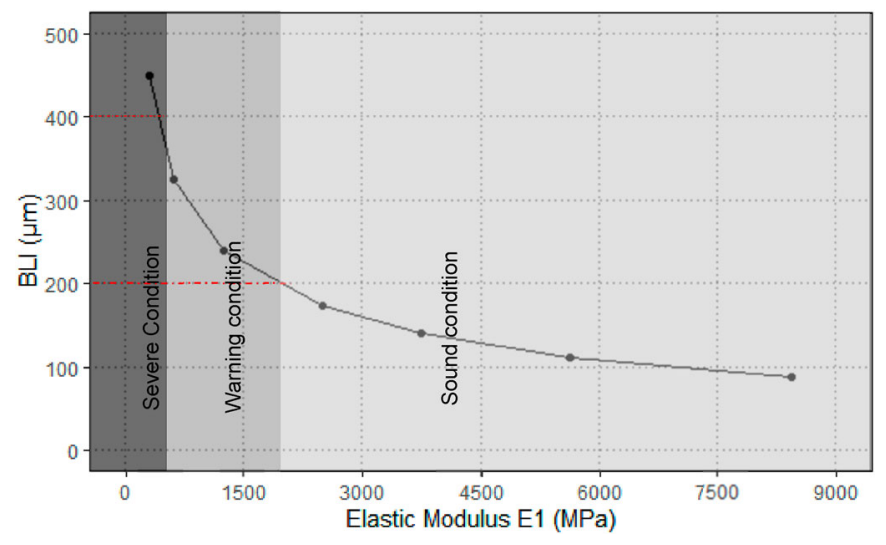

Figure 6. BLI sensitivity to HMA modulus $\left(E_{1}\right)$.

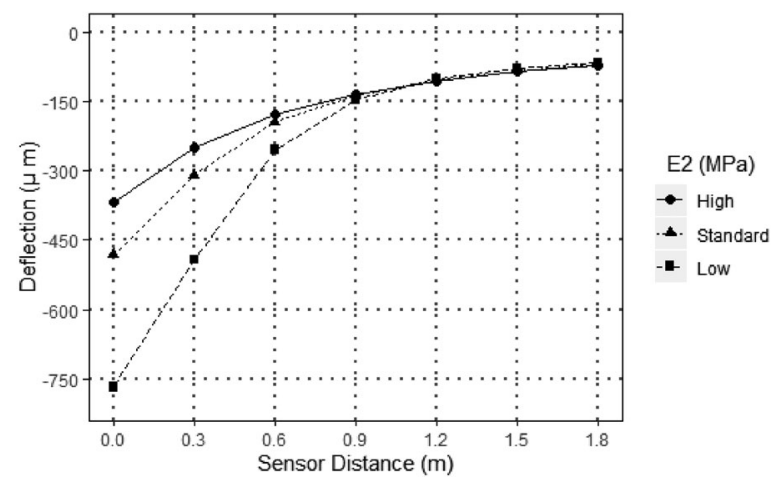

Figure 7. Effects of base modulus variations on the deflection basins.

lower than one, which is physically correct considering that as these particular parameters increase, one expects a better pavement structure, and hence, a lower probability of failure. The MLI model is consistently ranked as the best model by all the statistics (i.e. lowest AIC and BIC, and highest Log Likelihood and C-statistic, respectively).

In general, the results presented in Table 5 suggest that the MLI, defined as the difference between the deflections measured at $\mathrm{D}_{300}(300 \mathrm{~mm})$ and $\mathrm{D}_{600}(600 \mathrm{~mm})$ sensors, is the DBP parameter that best describes the base/subbase layer's structural behaviour, which is consistent with the findings reported by Horak (1987b). Note that the typical South African pavement structures with granular bases have relatively thin HMA surfacings (e.g. $40 \mathrm{~mm}$ to $50 \mathrm{~mm}$ ). Therefore, as described above in Table 2, the MLI here refers to the same zone in depth of the pavement structure similar to the Colombian typical pavement structures. Therefore, this parameter (MLI) was used to formulate the Logistic model for the base layer (see Equation 1). Details of the MLI model are presented in Table 6.

Table 6 presents the $\beta_{0}$ and $\beta_{1}$ parameters of the Logistic model associated with the middle base layer. The probability $p$-values presented in Table 6 indicate that the parameters are statistically significant, i.e. p-value $<0.05 \%$ at $95 \%$ CL. Moreover, for this specific case, the $\mathrm{OR}(1.02)=\exp (0.020$ * $1 \mu \mathrm{m})=1.02$, and implies that for one-unit increase in the MLI, one would expect to see a $2.0 \%$ increase in the odds of having a structural problem in the intermediate (middle) base layer.

Like for the HMA surfacing layer, Equation (1), with appropriate parameters taken from Table 6, was used to estimate the probability of failure/damage of the middle base layer with respect to MLI. The corresponding results are plotted in Figure 8.

According to Figure 8, a pavement with a MLI value greater than $245 \mu \mathrm{m}$ presents a high probability of structural failure (i.e. $75 \%$ probability of failure), indicating that the layer has a 'poor' structural condition. The results presented in Figure 8 are consistent with the threshold values proposed by Rabbi and Mishra (2019), where pavement structures with MLI $<115 \mu \mathrm{m}$ are considered to have a sound condition. Pavement structures with $115 \mu \mathrm{m}<\mathrm{MLI}<225 \mu \mathrm{m}$, on the other hand, are highlighted with a warning condition, and pavement structures with MLI $>225 \mu \mathrm{m}$ are considered to be in a critical condition, needing immediate intervention (Table 1). 
Table 5. Statistical results from probabilistic modelling - middle base layer.

\begin{tabular}{|c|c|c|c|c|c|c|c|}
\hline \multicolumn{8}{|c|}{ Middle base layer } \\
\hline \multirow[b]{2}{*}{ DBP's } & \multicolumn{2}{|c|}{ Parameters } & \multirow[b]{2}{*}{ OR } & \multirow[b]{2}{*}{ AIC } & \multirow[b]{2}{*}{ Log likelihood } & \multirow[b]{2}{*}{$\mathrm{BIC}$} & \multirow[b]{2}{*}{ C-statistic } \\
\hline & $\beta_{0}$ & $\beta_{1}$ & & & & & \\
\hline RoC & $\begin{array}{c}0.744 \\
(2 e-16)\end{array}$ & $\begin{array}{c}-0.000005353 \\
(2 \mathrm{e}-16)\end{array}$ & 1.00 & 6550.0 & -3272.9 & 6563.0 & 0.60 \\
\hline AUPP & $\begin{array}{c}3.660 \\
(2 e-16)\end{array}$ & $\begin{array}{c}-0.54467 \\
(2 \mathrm{e}-16)\end{array}$ & 0.58 & 6586.7 & -3291.3 & 6599.7 & 0.50 \\
\hline Area & $\begin{array}{c}1.487 \\
(2 \mathrm{e}-16)\end{array}$ & $\begin{array}{c}-0.00363 \\
(2 \mathrm{e}-16)\end{array}$ & 0.99 & 6586.7 & -3291.3 & 6599.7 & 0.50 \\
\hline AL2 & $\begin{array}{c}0.546 \\
(1.06 \mathrm{e}-05)\end{array}$ & $\begin{array}{c}-1.7523 \\
(4.49 \mathrm{e}-15)\end{array}$ & 0.17 & 6677.8 & -3336.8 & 6690.8 & 0.50 \\
\hline AL3 & $\begin{array}{c}1.396 \\
(2 \mathrm{e}-16)\end{array}$ & $\begin{array}{c}-5.01451 \\
(2 \mathrm{e}-16)\end{array}$ & 0.00 & 6216.6 & -3106.2 & 6229.6 & 0.59 \\
\hline \multicolumn{3}{|c|}{ Criterion (preferred value) } & & Lower & Higher & Lower & Higher \\
\hline
\end{tabular}

*The values in parentheses correspond to the $p$-value of the corresponding parameter.

Furthermore, as seen from Figure 9, the MLI exhibits a significant reduction as the elastic modulus of the middle base layer increases, with the slope seemingly to stabilise for modulus higher than $220 \mathrm{MPa}$ (i.e. layers in good condition). Therefore, this suggests that the MLI is highly sensitive to detect potential structural problems in the middle base layer. Horak and Emery (2006), Horak et al. (2015a) indicated that the general use of cement stabilised subbases tend to have much higher effective elastic moduli initially before cracking and breaking down to equivalent granular material state towards the end of such pavement structures' structural lives. Horak et al. (2015a) therefore concluded that the MLI in such cases may be less reliable to consistently predict the structural condition of this middle zone in the flexible pavement structure.

\section{Lower layer analysis - the subgrade}

Figure 10 shows that the subgrade modulus has a significant influence on the deflection basin. It is interesting to see that although changes in the elastic modulus of the HMA and base layers (Figures 4 and 7) only have an influence on the deflections measured near the loading point, changes in the subgrade modulus affect the entire deflection basin. One can see that the entire deflection basin is shifted as the subgrade modulus changes.

Table 7 presents details and corresponding results of the different probabilistic models proposed to analyse the subgrade based on relevant DBPs using Equation (1). Models based on AUPP and Area can be discarded considering that their parameters $\left(\beta_{0}\right.$ and $\left.\beta_{1}\right)$ are not statistically significant (i.e. $p$-values higher than 0.05 ), and hence, presents unstable models with OR values approaching to infinity. The model using AL4 has a problem with the $\beta_{0}$ parameter (i.e. $p$-value higher than 0.05), and hence, it presents an unstable model with an OR value approaching zero. The model based on the

Table 6. MLI model results - middle base layer.

\begin{tabular}{lccccr}
\hline Parameter & Estimate & S.E & Z & $p$-value & OR \\
\hline$\beta_{0}$ & -3.78 & 0.11 & -32.97 & $<0.001$ & \\
$\beta_{1}$ & 0.020 & 0.00 & 30.64 & $<0.001$ & 1.02 \\
Criterion & & & & $<0.05 \% @ 95 \% \mathrm{CL}$ & $>1.00$
\end{tabular}

Note: Legend: S.E. = Standard Error; Z = Standard Score; OR = Odds Ratio.
LLI presents adequate statistics and a good C-statistic with a value of 0.68 . Based on the criteria and statistical indicators listed in Table 7, the DBP selected to detect potential structural problems in the subgrade was the LLI.

Table 8 details the model parameters defined in Equation (1) for the subgrade using LLI as the predictive DBP variable. In general, the results show a good fit for the model with $p$ values significantly less than 0.05 at $95 \%$ CL.

Similar to the HMA surfacing and base layers, Equation (1), with appropriate parameters taken from Table 8, was used to estimate the probability of failure/damage of the subgrade with respect to LLI. The corresponding results are shown in Figure 11.

According to Figure 11, a pavement with a LLI value greater than $180 \mu \mathrm{m}$ presents a high probability of structural failure/ damage (i.e. $75 \%$ probability of failure), indicating that the subgrade has a 'poor' structural condition. Interestingly, the results presented in Figure 11 are also consistent with the threshold values proposed by Rabbi and Mishra (2019), where pavement structures with $\mathrm{LLI}<65 \mu \mathrm{m}$ are considered to have a sound condition, while pavement structures with $65 \mu \mathrm{m}<\mathrm{LLI}<120 \mu \mathrm{m}$ are highlighted with a warning condition and pavement structures with LLI $>120 \mu \mathrm{m}$ are considered to be in a critical condition, calling for immediate remediation (Table 1).

Additionally, Figure 12 shows a sensitivity analysis of the LLI as a function of the subgrade modulus. From the figure,

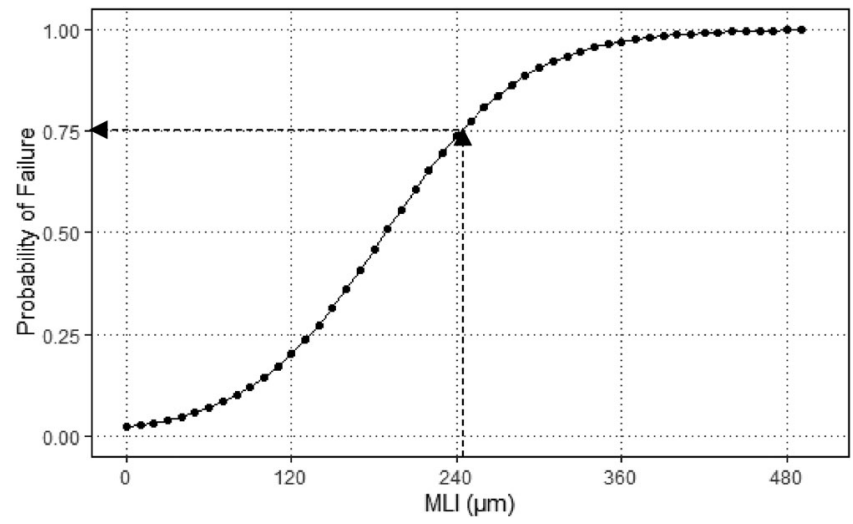

Figure 8. MLI probability of failure - middle base layer. 


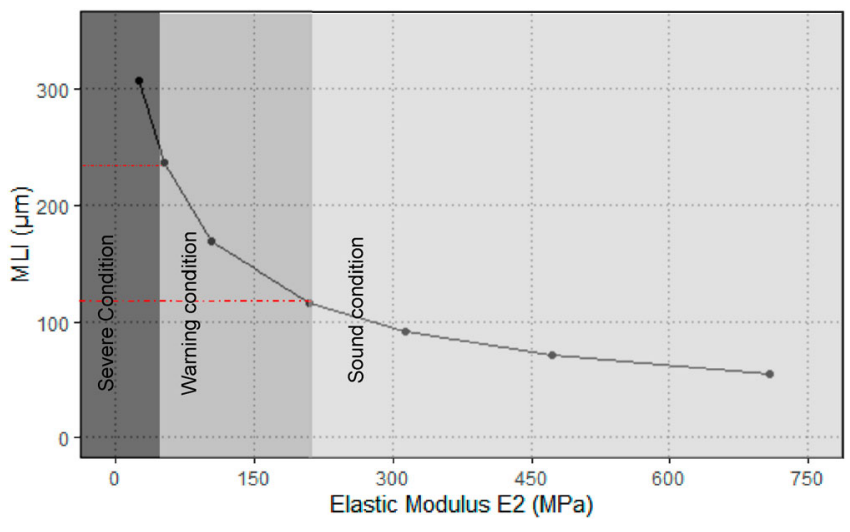

Figure 9 .\#MLI sensitivity to base modulus (E2).

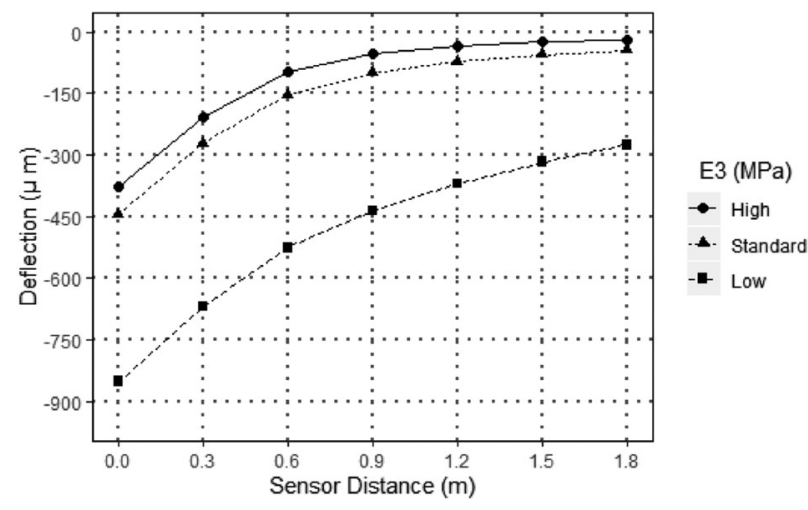

Figure 10. Effects of subgrade modulus variation on the deflection basins.

one can distinguish that the slope of the relationship between LLI and E3 seems to stabilise for moduli values higher than $100 \mathrm{MPa}$ (i.e. layers in good condition). This further suggests that the LLI is highly sensitive to detect potential structural problems in the subgrade.

\section{Synthesis and discussions}

The methodology proposed in this study allows pavement agencies to quickly and economically assess structural problems in flexible pavements based on Deflection Basin Parameters (DBP) obtained through measurements obtained with a Falling Weight Deflectometer (FWD). This is particularly significant and beneficial for network level assessment.
Table 9 presents data (thresholds) related to the probability failure of specific pavement layers associated with the DBP's. A remarkable aspect of this research study is that the proposed models allow to identify problems in the structural condition of each of the layers that make up the pavement structure, without having prior information on their physical and/or mechanical characteristics, i.e. modulus, thickness, Poisson ratio, etc. Therefore, the models and thresholds proposed herein constitute a helpful tool that could assist the decision making process at the network level assessment for flexible pavements, identifying which pavement sections require further detailed and targeted evaluation studies (i.e. sitespecific) at project level assessment.

Table 9 proposes thresholds for each DBP with its corresponding probability of failure for each corresponding pavement layer. Usage of these thresholds could allow pavement agencies to timely schedule and prioritise interventions, either preventive or corrective, solely by conducting deflection measurements on the road network. According to Table 9, a flexible pavement that presents a $306 \mu \mathrm{m}<\mathrm{BLI}<365 \mu \mathrm{m}$ is considered to have a failure probability between $25 \%$ to $75 \%$ in its top layer. Likewise, if a flexible pavement presents an MLI value of less than $134 \mu \mathrm{m}$ suggests that its intermediate base layer has a probability of failure of less than $25 \%$. The same interpretative analysis applies to all the DBP thresholds listed in Table 9.

\section{Summary and conclusions}

This paper presented the results of a study that focused on the development of analytical and statistical tools that seek to aid road agencies with the prioritisation of maintenance and rehabilitation $(M \mho R)$ activities, at the network level assessment, based on various structural performance indicators (i.e. Deflections Bowl Parameters - DBP). A comprehensive database composed of 5000 pavement sections with different elastic moduli and thicknesses for each layer was generated using the Monte Carlo simulation technique.

The mechanical response (deflections) under falling weight deflectometer (FWD) loading of each pavement section that comprised the database was modelled using commercially available multi-layer linear elastic software. The results were then used to calculate different DBPs associated with each pavement sections. Probabilistic models that allow for analysing, at the network level assessment, the condition of a flexible

Table 7. Statistical results from probabilistic modelling - subgrade.

\begin{tabular}{|c|c|c|c|c|c|c|c|}
\hline \multicolumn{8}{|c|}{ Subgrade layer } \\
\hline \multirow[b]{2}{*}{$\mathrm{DBP}^{\prime} \mathrm{s}$} & \multicolumn{2}{|c|}{ Parameters } & \multirow[b]{2}{*}{ OR } & \multirow[b]{2}{*}{ AIC } & \multirow[b]{2}{*}{ Log likelihood } & \multirow[b]{2}{*}{$\mathrm{BIC}$} & \multirow[b]{2}{*}{ C-statistic } \\
\hline & $\beta_{0}$ & $\beta_{1}$ & & & & & \\
\hline AUPP & $\begin{array}{l}-661.62 \\
(0.991)^{*}\end{array}$ & $\begin{array}{r}81.61 \\
(0.992)\end{array}$ & $a$ & 4 & -3291.35 & 17.03 & 0.99 \\
\hline Area & $\begin{array}{c}-335.18 \\
(0.992)\end{array}$ & $\begin{array}{r}13.6 \\
(0.992)\end{array}$ & $a$ & 4 & $-1.26 \mathrm{e}-07$ & 17.03 & 0.99 \\
\hline $\begin{array}{l}\text { LLI } \\
\qquad\left(D_{600}-D_{900}\right)\end{array}$ & $\begin{array}{c}-3.755 \\
(2 \mathrm{e}-16)\end{array}$ & $\begin{array}{r}0.027 \\
(2 \mathrm{e}-16)\end{array}$ & 1.02 & 4651.8 & -2323.8 & 4664.8 & 0.68 \\
\hline AL4 & $\begin{array}{c}0.1618 \\
(0.311)\end{array}$ & $\begin{array}{l}-48.37 \\
(2 \mathrm{e}-16)\end{array}$ & 0.00 & 4911.2 & -2453.6 & 4924.22 & 0.56 \\
\hline \multicolumn{4}{|c|}{ Criterion (preferred value) } & Lower & Higher & Lower & Higher \\
\hline
\end{tabular}

*The values in parentheses correspond to the $p$-value of the corresponding parameter. 
Table 8. Modelling results - the subgrade.

\begin{tabular}{lrlccr}
\hline Parameter & Estimate & S.E & $Z$ & $p$-value & OR \\
\hline$\beta_{0}$ & -3.755 & 0.14 & -26.09 & $<0.001$ & \\
$\beta_{1}$ & 0.027 & 0.001 & 18.00 & $<0.001$ & 1.03 \\
Criterion & & & & $<0.05 @ 95 \% \mathrm{CL}$ & $>1.00$ \\
\hline
\end{tabular}

Note: Legend: S.E. = Standard Error; Z = Standard Score; OR= Odds Ratio.

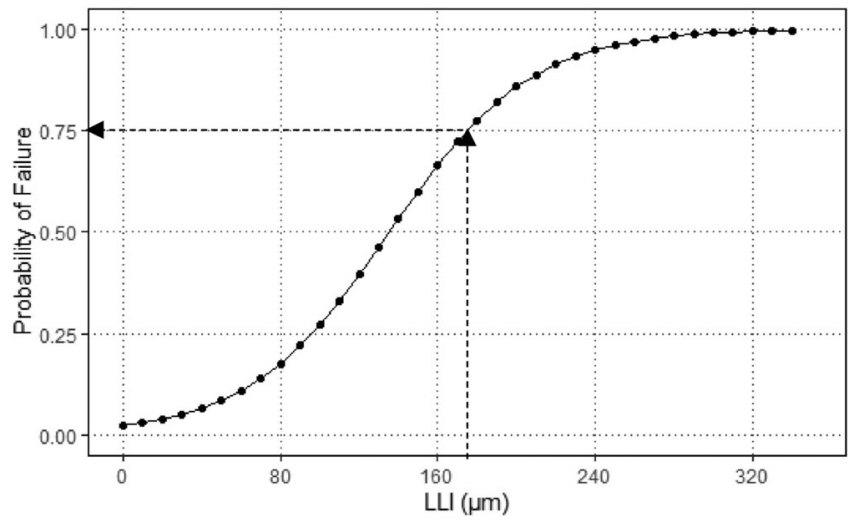

Figure 11. LLI probability of failure - the subgrade.

pavement, from relevant DBPs, identifying/detecting which layers of the pavement structure present a probability of structural failure/damage were formulated. Based on the results presented in this paper, the following conclusions and recommendations were drawn:

- The DBPs can successfully be used to assess the structural integrity of a specific layer of a pavement structure. Furthermore, the statistical models developed could be used to estimate the probability that a specific layer is compromised and/or susceptible to failure/damage. These statistical (probabilistic) models could be used in lieu of the threshold ranges available in the literature to identify potential problems in a pavement structure for network level assessment.

- The Base Layer Index (BLI) was found to be the best DBP parameter that could be used to assess the structural integrity of the HMA surfacing layer. The statistical results suggested that pavement structures with BLI values
Table 9. Proposed threshold values associated with the DBPs.

\begin{tabular}{lccc}
\hline & \multicolumn{3}{c}{ Deflection bowl parameters (DBP's) } \\
\cline { 2 - 4 } $\begin{array}{l}\text { Probability of failure } \\
(\%)\end{array}$ & $\begin{array}{c}\text { HMA surface BLI } \\
(\mu \mathrm{m})\end{array}$ & $\begin{array}{c}\text { Middle layer MLI } \\
(\mu \mathrm{m})\end{array}$ & $\begin{array}{c}\text { Subgrade LLI } \\
(\mu \mathrm{m})\end{array}$ \\
\hline$<25$ & $<306$ & $<134$ & $<96$ \\
$25-75$ & $306-365$ & $134-245$ & $96-180$ \\
$>75$ & $>365$ & $>245$ & $>180$ \\
\hline
\end{tabular}

exceeding $365 \mu \mathrm{m}$ have $75 \%$ probability that the HMA surfacing layer is structurally compromised. In addition, it was identified that the BLI is highly sensitive to the HMA elastic modulus, particularly for values lower than $1500 \mathrm{MPa}$.

- The Middle Layer Index (MLI) was identified as the best DBP parameter to assess the structural integrity of the middle base layer. The statistical results suggested that pavement structures with MLI values exceeding $245 \mu \mathrm{m}$ have $75 \%$ probability that the base layer is structurally compromised. In addition, the MLI exhibited high sensitivity to the base layer modulus (elastic), particularly for values lower than $150 \mathrm{MPa}$.

- The Lower Layer Index (LLI) was identified as the best DBP parameter to evaluate and quantify the structural integrity of the subgrade. The statistical results suggested that pavement structures with LLI values exceeding $180 \mu \mathrm{m}$ have $75 \%$ probability that the subgrade is structurally compromised. Additionally, the LLI exhibited high sensitivity to the subgrade modulus (elastic), particularly for values lower than $50 \mathrm{MPa}$.

- The probabilistic models formulated in this study, namely the Logistic/Logit models, exhibited promising potential to analytically quantify the structural condition of flexible pavement structures. For the pavement structures and material properties considered, the formulated probabilistic models were satisfactorily able to analytically discriminate and differentiate the structural conditions of the various pavement layers including the HMA surfacing, middle base, and the subgrade, respectively.

Overall, the study contributes to the literature enrichment through proposition of a methodological criteria (DBP indices) with room for refinement including correlations and

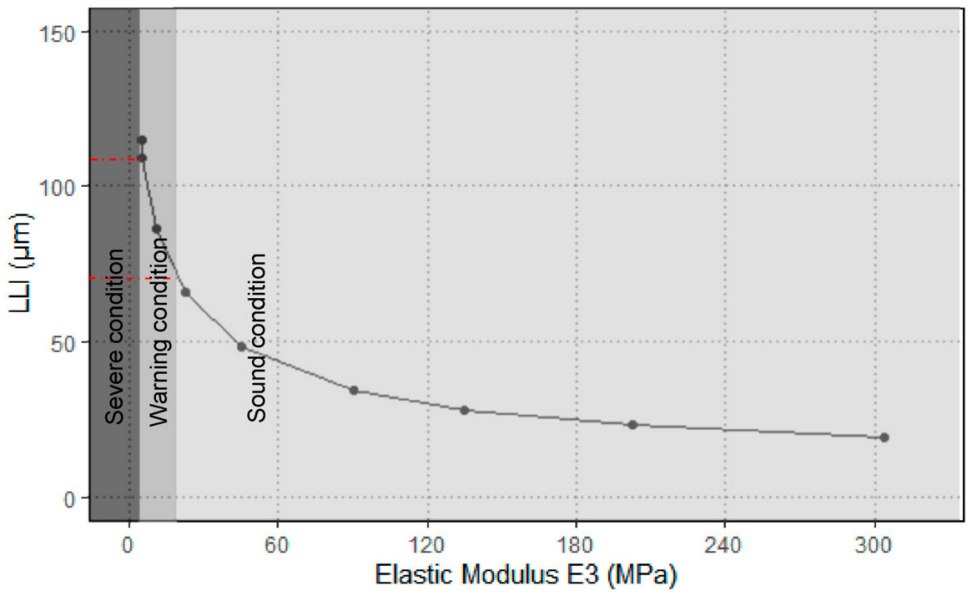

Figure 12. LLI sensitivity to subgrade modulus (E3). 
validation with field data. The methodology has the potential to allow pavement agencies to quickly and economically assess structural problems in flexible pavements based on Deflection Basin Parameters (DBP) obtained through measurements obtained with a Falling Weight Deflectometer (FWD) which is very critical and beneficial for network level assessment. Ultimately, this allows to timely schedule and prioritise maintenance interventions, either preventive or corrective, solely by conducting deflection measurements on the road network.

\section{Study limitations and potential future work}

Overall, the analytical/statistical models proposed in study provided a useful and objective tool for quantifying, at network level, the structural condition of pavement structures - thus, allowing for timely $M \leftrightarrow R$ decisions and optimisation of resources. However, efforts, in future studies, should be conducted to develop probabilistic models for different pavement structures and material properties taking into account the limitations of this study. For instance, the study was limited to traditional flexible pavements with untreated granular base layers using Colombian standards as the reference datum - without consideration of treated bases/sub-bases such cement (CTB), lime treated (LTB), bituminous bases, etc. Therefore, using the results and findings of this study as a reference guide, future follow-up studies should cover a more broader array of pavement structures and materials including the viscoelastic modelling of the hot-mix asphalt (HMA), moisture/stress sensitivity of the base and subgrade, etc.

However in spite of the limitations to this simplified approach used with the DBPs described above, the results indicate that the approach can be used with confidence for network level assessment to monitor the performance and estimate/

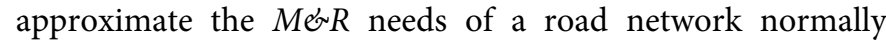
described in Pavement Management Systems. As indicated by Horak et al. (2015b) the possibility of also linking DBPs with the internationally known Structural Number (SN) shows great promise to use DBPs directly for such network level performance or SN derived from FWD DBPs. This clearly overcomes the problems described above to do detailed back analyses of effective elastic moduli of the pavement layers and then mechanistic analyses for more detailed network level pavement performance analyses.

Lastly, it should also be noted that the results presented herein pertain to the pavement structures and material properties evaluated in this study. Therefore, the overall findings and conclusions may not be exhaustive nor exclusive.

\section{Acknowledgements and disclaimer}

The authors thank all those who assisted, in one way or another, during the course of this study as well as the documentation of this paper. The contents of this paper reflect the views of the authors who are solely responsible for the facts and accuracy of the data presented herein and do not necessarily reflect the official views or policies of any agency or institute. This paper does not constitute a standard, specification, nor is it intended for design, construction, bidding, contracting, tendering, certification, or permit purposes. Trade names were used solely for information purposes and not for product endorsement, advertisement, promotions, or certification.

\section{Disclosure statement}

No potential conflict of interest was reported by the author(s).

\section{ORCID}

Luis Fuentes (D) http://orcid.org/0000-0002-7811-8821

\section{References}

AASHTO, 1993. AASHTO guide for design of pavement structures 1993. Washington, DC: American 7 Association of State Highway and Transportation Officials.

Abudinen, D., Fuentes, L., and Carvajal, J., 2017. Travel quality assessment of Urban Roads based on International roughness Index: case study in Colombia. Transportation Research Record: Journal of the Transportation Research Board, 2612 (1), 1-10.

Adams, J. and Kim, R., 2014. Mean profile depth analysis of field and laboratory traffic-loaded chip seal surface treatments. International Journal of Pavement Engineering, 15 (7), 645-656.

Alkasawneh, W., 2007. Backcalculation of pavement moduli using genetic algorithms. Ph.D. thesis, Department of Civil Engineering, University of Akron.

Anderson, D., 1977. The design of asphalt concrete overlays for flexible highway pavements. Berkeley: Departament of civil Engineering. University of California.

Dehlen, G., 1961. The use of the Benkelman beam for the measurement of deflections and curvatures of a road surface between dual wheels. Council for Scientific and Industrial Research (CSIR) special report, R.2. Pretoria.

Dehlen, G., 1962. Flexure of a road surfacing, its relation to fatigue cracking, and factors determining its severity. HRB, Highway Research Board Boletin no. 321.

FHWA, 2016. Pavement structural evaluation at the network level: final report. Federal Highway Administration. Publication no. FHWAHRT15/074.

Fuentes, L., et al., 2012. Determination of pavement macrotexture limit for use in international friction index model. Transportation Research Record: Journal of the Transportation Research Board, 2306 (1), 138-143.

Fuentes, L., et al., 2019. Modelling pavement serviceability of urban roads using deterministic and probabilistic approaches. International Journal of Pavement Engineering. doi:10.1080/10298436.2019.1577422.

Fuentes, L. and Gunaratne, M., 2010. Evaluation of the Speed Constant and Its Effect on the Calibration of Friction-Measuring Devices. Transportation Research Record: Journal of the Transportation Research Board, 2155. Washington, DC: Transportation Research Board of the National Academies, 134-144.

Fuentes, L. and Gunaratne, M., 2011. Revised Methodology for Computing International Friction Index Transportation Research Record: Journal of the Transportation Research Board, 2227. Washington, DC: Transportation Research Board of the National Academies, 129-137.

Fuentes, L., Gunaratne, M., and Hess, D., 2010. Evaluation of the effect of pavement roughness on skid resistance. Journal of Transportation Engineering, 136 (7), 640-653.

Garg, N. and Thompson, M., 1997. Mechanistic-empirical evaluation of the Mn/road low volume road test sections. ProQuest dissertations.

Gopalakrishna, K. and Kumar, S., 2010. Finite element based adaptive neuro-fuzzy inference technique for parameter identification of multi-layered transportation structures. Transport, 25 (1), 58-65.

Harrison, R., 2010. Introduction to Monte Carlo simulation. AIP Conference Proceedings, 1204, 17-21.

Hoffman, M. and Thompson, M., 1981. Mechanistic interpretation of nondestructive pavement testing deflections. ProQuest dissertations. 
Horak, E., 1987a. The use of deflection basin measurments in the mechaninistic analysis of flexible pavements. Sixth international conference on the structural design of asphalt pavements, vol. 1. University of Michigan.

Horak, E., 1987b. Aspects of deflection basin parameters used in a mechanistic rehabilitation design procedure for flexible pavements in South Africa. PhD thesis. Pretoria: Department of Civil Engineering, University of Pretoria.

Horak, E., 2008. Benchmarking the structural condition of flexible pavements with deflection bowl parameters. Journal of the South African Institution of Civil Engineers, 50 (2), 2-9.

Horak, E. and Emery, S., 2006. Falling weight deflectometer bowl parameters as analysis tool for pavement structural evaluations. In: Proceedings of 22nd ARRB conference. Canberra.

Horak, E., Emery, S., and Maina, J., 2015a. Review of falling weight deflectometer deflection benchmark analysis on roads and airfields. In: 11th conference on asphalt pavements for Southern Africa: CAPSA15, 16-19 August 2015, Sun City.

Horak, E., Hefer, A., and Maina, J., 2015b. Modified structural number determined from falling weight deflectometer bowl parameters and its porposed use ina Benchmark methodology. Journal of Traffic and Transportation Engineering, 3. doi:10.17265/2328-2142/2015.04.000.

Hosmer, D., Lemeshow, S., and Sturdivant, R., 2013. Applied logistic regression. New York: Wiley. Incorporated.

Hossain, M. and Zaniewski, J., 1991. Characterization of falling weight deflectometer deflection basin. Transportation Research Record: Journal of the Transportation Research Board, 1293. Washington, DC: Transportation Research Board of the National Academies, 1 - 11.

$\mathrm{Hu}, \mathrm{X}$., et al., 2010. Proposed loading waveforms and loading time equations for mechanistic-empirical pavement design and analysis. Journal of Transportation Engineering, 136 (6), 518-527.

INVIAS, 2018. Especificaciones generales de construcción de carreteras y normas de ensayo para materiales de carreteras. Insituto Nacional de Vias Ministerio de Transporte de la República de Colombia.

Joubert, F., 1992. Structural Classification of granular base pavement using measured deflection bowl parameters. ProQuest dissertations. Rand Afrikaans University.

Kennedy, C. and Lister, N., 1978. Deflection and pavement performance: the experimental evidence. TRRL Laboratory Report no. 833. Great Britain.

Kilareski, W. and Anani, B., 1982. Evaluation of in situ moduli and pavement life from deflection basins. Proceedings of the Fifth International Conference on the Structural Design of Asphalt Pavements Held Deflt University of Technology, 1 (2), 349-366.

Kim, Y., Ranjithan, S., Troxler, J., and Xu, B. 2000. Assessing pavement layer condition using deflection data. Final Report, NCHRP Project 10-48. North Carolina State University, Raleigh.

Kim, R. and Park, H., 2002. Use of falling weight deflectometer multi-load level data for pavement strength estimation. ProQuest dissertations.

Maree, J. and Bellekens, R., 1991. The effect of asphalt overlays on the resilient deflection bowl response of typical pavement structures. Research report RP 90/102 for the Department of Transport. Chief Directorate National Roads, Pretoria, 1991.

Pencina, M. and D'Agostino, R., 2015. Evaluating discrimination of Risk Prediction models. JAMA The Journal of the American Medical Association, 314 (10), 1063-1064. doi:10.1001/jama.2015.11082.

Rabbi, M. and Mishra, D., 2019. Using FWD deflection basin parameters for network-level assessment of flexible pavements. International Journal of Pavement Engineering, 1-15. doi:10.1080/10298436.2019. 1580366.

Rohde, G. and Van Wijk, A., 1996. A mechanistic procedure to determine basin parameter criteria. Petroria: Southern African Transportation Conference.
Saleh, M., 2015a. Multi-scale criteria for structural capacity evaluation of flexible pavements at network level. In: Transportation research board 94th annual meeting for both presentation and publications.

Saleh, M., 2015b. Utilisation of the deflectograph data to evaluate pavement structural condition of the highway network. Road Materials and Pavement Design, 17 (1), 136-152.

Saleh, M., 2016. A mechanistic empirical approach for the evaluation of the structural capacity and remaining service life of flexible pavements at the network level. Canadian Journal of Civil Engineering, 43, 749758. doi:10.1139/cjce-2016-0060.

Shahin, M., 2005. Pavement management for airports, roads and parking lots (2nd ed.). New York, NY: Springer.

Solanki, U., Gundalia, P., and Barasara, M., 2014. A review on structural evaluation of flexible pavements using falling weight deflectometer. Trends in Transport Engineering and Applications, 2 (1), 1-10.

Stubstad, R. and Connor, B., 1983. Use of the falling weight deflectometer to predict damage potential on Alaskan highways during spring thaw. Transportation Research Record: Journal of the Transportation Research Board, 930. Washington, DC: Transportation Research Board of the National Academies, 46-51.

Tarefder, R. and Mesbah, A., 2014. Modeling of the FWD deflection basin to evaluate airport pavements. International Journal of Geomechanics, 14 (2), 205-213.

Team, R., 2019. RStudio: integrated development for R. RStudio. Obtenido de http://www.rstudio.com/.

Terzi, S., et al., 2012. Backcalculation of pavement layer thickness using data mining. Neural Computing and Applications, 23 (5), 1369-1379. doi:10.1007/s00521-012-1083-2.

Tutumluer, E., 2015. Development of improved pavement rehabilitation procedures based. NEXTRANS Project No. 094IY04.

Vaswani, N., 1971. Method for separately evaluating structural performance of subgrades and overlaying flexible pavements. HRB, Highway Research Record No.362.

Vrtis, M., 2017. Investigation of deflection basin to identify structural distresses within flexible pavements. ProQuest dissertations.

Walubita, L.F., et al., 2012. Texas flexible pavements and overlays: year 1 report, test sections, data collection, analyses, and data storage system (No. FHWA/TX-12/0-6658-1). Texas Transportation Institute (TTI). National Technical Information Service Alexandria, Virginia 22312.

Walubita, L.F., et al., 2017. Texas flexible pavements and overlays: year 5 report-complete data documentation (No. FHWA/TX-15/0-6658-3). Texas A\&M Transportation Institute (TTI). National Technical Information Service Alexandria, Virginia 22312.

Walubita, L.F., Liu, W., and Scullion, T., 2010. Texas perpetual pavements: experience overview and the way forward (No. FHWA/TX-10/0-4822 3). College Station, TX: Texas Transportation Institute (TTI).

Wang, Y. and Liu, Q., 2006. Comparison of Akaike information criterion (AIC) and Bayesian information criterion (BIC) in selection of stock-recruitment relationships. Fisheries Research, 77 (2), 220-225.

Whitcomb, W., 1982. Surface deflections and pavement evaluation equipment and analysis techniques. Transportation Engineering Report 82-4. Cornwallis, OR: Oregon State University.

Xu, B., Ranji Ranjithan, S., and Kim, R., 2002. New relationships between falling weight deflectometer deflections and asphalt pavement layer condition indicators. Transportation Research Record: Journal of the Transportation Research Board, 1806 (1), 46-56.

Zheng, Y., Zhang, P., and Liu, H., 2019. Correlation between pavement temperature and deflection basin form factors of asphalt pavement International Journal of Pavement Engineering, 20 (8), 874-883. doi:10.1080/10298436.2017.1356172. 